\title{
Hydrophilic Improvement of PET Fabrics Using Plasma-Induced Graft Polymerization
}

\author{
Nguyen Kien Cuong, Noboru SAeki ${ }^{*}$, Seiichi Kataoka * * \\ and Susumu YoshiKawA *** \\ Production Technology Department, Technology Research Institute of Osaka Prefecture, 7-1 Ayumino 2, Izumi, Osaka 594-1157 \\ *Pearl Kogyo Co., Ltd., 8-13 Minami-Kagaya 3-chome, Suminoe, Osaka 559-0015 \\ * * Organic Materials Department, Osaka National Research Institute, Midorigaoka, Ikeda, Osaka 563-8577 \\ ${ }^{* * *}$ Institute of Advanced Energy, Kyoto University, Gokasho, Uji, Kyoto 611-0011
}

(Received September 26, 2000 ; Accepted January 7, 2002)

\begin{abstract}
Poly(ethylene terephthalate) (PET) fiber knit-fabrics were irradiated by glow-discharge plasma (GDP) at oneatmosphere, then subsequently grafted with a hydrophilic acrylic acid (AA). Degradation of GDP-treated surface was determined by weight loss ratio. This degradation is proportional to time of exposure. The wicking-time method was used for roughly estimating hydrophilic durability of grafted surfaces versus the time of exposure and times of washing. On the grafted surface, characterized by X-ray photoelectron spectroscopy (XPS), carbon contents $\mathrm{C}_{1 \mathrm{~s}}$ decreased while oxygen contents $\mathrm{O}_{1 \mathrm{~s}}$ considerably increased. This results in an amount of oxygen polar functional groups like carboxylic $\left(\mathrm{O}-\mathrm{C}^{*}=\mathrm{O}\right)$ and carbonyl $\left(\mathrm{C}^{*}=\mathrm{O}\right)$ groups introduced into the grafted surface. Grafted surface morphology observed by scanning electron microscopy (SEM) displays some large area of corn-structure compared to relative smooth morphology of the control fabric. It also suggested that hydrophilic improvement was closely related to oxygen containing functional groups incorporated onto the grafted fiber surface and the surface roughness.
\end{abstract}

\section{Introduction}

Hydrophilicity or hydrophobia is closely related to physico-chemical properties of a fiber surface-layer. Textile fabrics produced by poly(ethylene terephthalate) (PET) fibers cannot usually absorb moisture and be dyed at one-atmosphere owing to the high degree of crystalline, density and lack of functional polar groups on the fiber's surface such as $-\mathrm{COOH}$ and $-\mathrm{OH}$. This causes the fiber to have low surface free energy and poor wettability. PET fiber fabrics, therefore, require surface modifycation to improve their hydrophilicity.

Surface modification is usually used to roughen fiber surfaces to enhance mechanical interlocking, and form chemical groups on the surface that improve wetting and/or chemical bonding. ${ }^{1)}$ The conventional surface modifications have been performed by various chemical treatments. These processes are usually accompanied with damaging bulk fibers, and affect fiber's properties. ${ }^{2}$

E-mail: Cuong@ tri.pref.osaka.jp
Exposed to glow-discharge plasma (GDP), polymer fibers can enhance theirs dyeing behavior, moisture absorption, and especially surface adhesion etc. Furthermore, the surface modified by the GDP is, in general, confined to a thin layer less than $100 \mu \mathrm{m}$. And desirable properties of bulk materials are usually maintained.

The GDP has been applied to surface modification of polymers since more than two decades., ${ }^{3,4}$ Most of works have so far dealt with the GDP at low pressure less than $133 \mathrm{~Pa}$ and ambient temperature. Chen et al. ${ }^{5}$ studied effects of gas types on wettability of PET films treated at low-pressure plasma. Irradiated by various gases for short time; the film showed its hydrophilicity. Later, Carlotti et al. modified PET fibers with argon and oxygen plasma to enhance the adhesion between the fiber and rubber matrices. Adhesion strength measured by peeling tests of the treated fiber was considerably increased. ${ }^{6}$ Moreover, effects of discharge power, time of exposure and gas-pressure on improvement in wettability, dyeing and bonding capability of various polymer fibers were also investigated. ${ }^{7 \sim 10)} \mathrm{Nev}-$ ertheless, the plasma process at low pressure has not 
widely been developed in the textile industry as its reactors were used in high vacuum that is not familiar with conventional textile machine lines.

Recently, high compact plasma reactors, which even operated at one-atmosphere and room temperature, have been developed. Kanazawa et al. tried to establish stable-glow plasma at an atmospheric pressure with various gas-types and $\mathrm{He}$ used as the diluted gas. States of discharge plasma and contact angles on the PET film's surface treated by such plasma were compared to those of the surface irradiated at the lowpressure plasma. ${ }^{11)}$ Later, Tsai et al. have reported significant changes in the plasma treated surface of the polypropylene melt-blown non-woven fabric. Treated at one-atmosphere in the GDP reactor developed in their laboratory ${ }^{12}$, the fabric considerably improved in wettability, wickability, and surface free energy.

However, most of the papers mentioned above were concerned in plasma irradiation to improve hydrophilicity of the fiber surface, even some of them also reported that the plasma treated surface gradually restored its hydrophobia ${ }^{13)}$ as fragmented low polymerchains on the surface reoriented into the hydrophobic bulks resulting in decreasing a number of functional groups on the treated surface. ${ }^{14,15)}$ Nevertheless, none of papers has yet reported how to maintain the functional groups to be stable for a long time on the fiber surface.

In order to develop plasma technique on an industrial scale, the modified surface should be stable in time. In fact, aging effects can be slowed down and fiber's wettability will be improved if the functional groups are grafted with hydrophilic monomers because plasma-induced graft polymerization not only maintains durability of the polar groups but also provides chemical modification by the covalent bonding of new molecular on top of the fiber. This method also imparts additional properties on the fiber surface without effects on the bulk properties by a careful selection of suitable monomers.

In this study, PET fiber knit-fabrics were irradiated with a mixture of helium-argon gases at atmospheric pressure, subsequently grafted with hydrophilic monomer like acrylic acid (AA) to enhance theirs durable hydrophilicity. Effects of various time of the irradiation on fabric's wettability were investigated. Grafting degree and wicking time were measured to roughly estimate hydrophilic capability of the treated fabric. Chemical compositions of the control surface characterized by X-ray photoelectron spectroscopy (XPS) were compared to those of the surface treated by plasma-induced graft polymerization. And, changes in morphology of the grafted surface compared to the control one were observed by scanning electron microscopy (SEM).

\section{2 . Experimental Procedure}

\section{1 Sample preparation}

Rib fabric, supplied by Nissin Fiber Co., Ltd., Japan, was fabricated using 75 denier PET fibers. Their stitch densities, corresponding to weight of $135 \mathrm{~g} / \mathrm{m}^{2}$, measured in the wale and course directions were 44 loops and 59 loops per inch, respectively.

The PET fiber fabric demonstrates the high resistance to water penetration. Wicking time is over $900 \mathrm{~s}$ when placing a distilled water droplet of $10 \mu \mathrm{l}$ on the fabric's surface until the droplet completely looses its reflective power. Figure 1 (a) illustrates the knitfabric's structure. Curve yarns oriented in threedimensional direction interlock together and are created into knitted loops with a loosen structure and air space being inside. In PET polymer structure, shown in Fig. 1 (b), the aromatic ring and its associated $\mathrm{C}-\mathrm{C}$ bonds provide rigidity to the structure. And furthermore, fragmentation of PET polymer chains on the fiber surface might occur at $\mathrm{C}-\mathrm{H}$ and $\mathrm{C}-\mathrm{C}$ molecular bonds when the polymer chain absorbs energies from

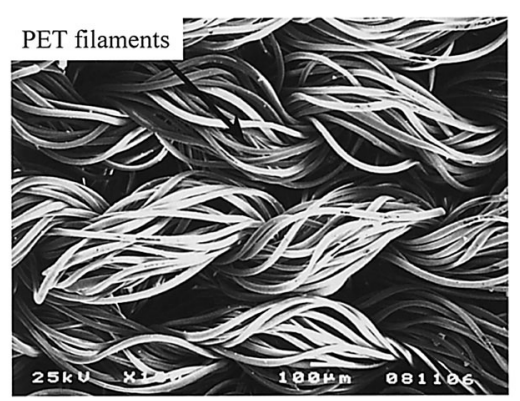

(a)

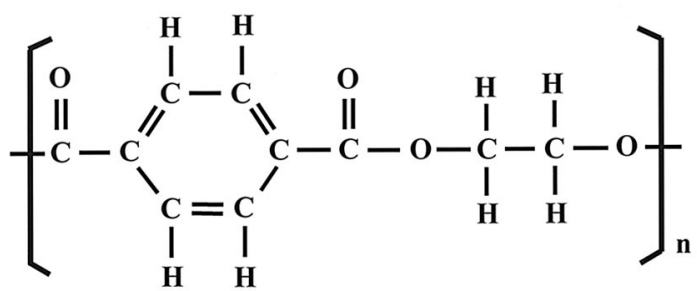

(b)

Fig. 1 SEM micrograph of (a) the PET fiber knit-fabric and (b) PET polymer structure. 


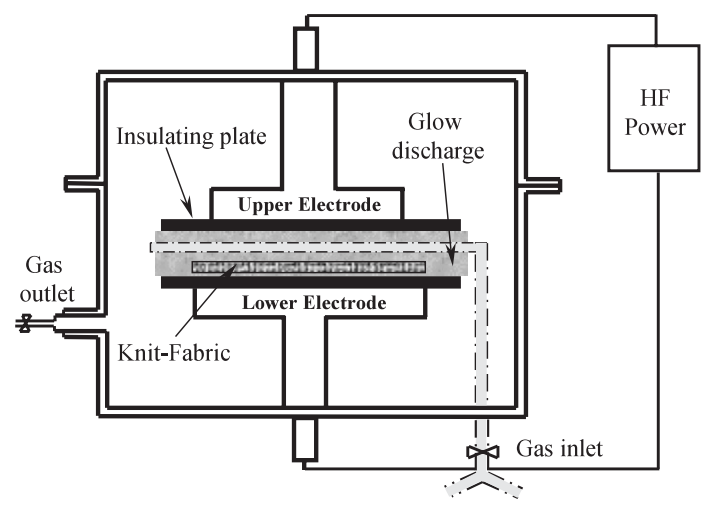

Fig. 2 Schematic diagram of a reactor generated with glow discharge plasma at one-atmosphere.

activated species during plasma irradiation.

Washed in $60^{\circ} \mathrm{C}$ neutral-detergent water to remove starch, grease and colloids attached to fiber surfaces, a sample of $120 \times 120 \mathrm{~mm}$ was dried in a vacuum desiccator.

A glow discharge at one-atmosphere was generated in a parallel-plate electrodes covered with dielectric barriers of a conventional plasma reactor operated at $20 \mathrm{kHz}$ (Fig. 2). The sample placed between two electrodes was exposed to a mixture of $\mathrm{He}-\mathrm{Ar}$ inert gases. The major component, He gas, possessing a great amount of energy is necessary to sustain the GDP. The addition of Ar gas molecules possessing much lower excited energy level but longer the lifetime than those of He gas leads to increase the density of discharge carriers. A mixture of $\mathrm{He}-\mathrm{Ar}$ gases constantly flowed into a discharge region with a ratio of $850 \mathrm{ml} / 150 \mathrm{ml}$ $\min ^{-1}$ (STP), respectively. Samples were irradiated with time of exposure varied from $10 \mathrm{~s}$ to $3 \mathrm{~min}$.

The sample was immediately weighted to estimate degradation of surface-layer polymers after the GDP treatment. The polymer degradation characterized by weight-loss ratio was calculated in the following expression:

$$
W_{\mathrm{L}}(\%)=\frac{W_{0}-W_{1}}{W_{1}} \times 100
$$

Where: $W_{\mathrm{L}}(\%)$ is the weight-loss ratio; $W_{0}$ and $W_{1}$ are the weight of a sample before and after the GDP treatment. The irradiated sample was then grafted with AA ( $99.5 \%$ conc.) in a glass tube evacuated to $133 \mathrm{~Pa}$ at two levels of constant temperature: $60^{\circ} \mathrm{C}$ as well as 70 ${ }^{\circ} \mathrm{C}$; the grafting process lasted for $8 \mathrm{~h}$ and $1 \mathrm{~h}$, respectively.

Taken from the glass tube, the sample was extracted by hot methanol in a Soxhlet extractor for over $2 \mathrm{~h}$ to remove unreacted remaining monomer. The wettabil- ity of the grafted sample was characterized by the grafting degree, which was used to estimate the degree of the glow discharge subsequent to graft polymerization:

$$
\text { Grafting degree }(\%)=\frac{W_{2}-W_{1}}{W_{1}} \times 100
$$

Where: $W_{1}$ and $W_{2}$ are the sample's weight measured before and after the graft polymerization, respectively.

\section{2 Washing durability of the treated fabric}

The grafted sample was washed several times in the neutral-detergent water at $60^{\circ} \mathrm{C}$; the durable wettability was estimated by the wicking technique. A droplet of distilled water was introduced on the grafted surface by a micro syringe and time for the droplet completely loosing its reflective power was measured.

\subsection{Surface characterization of the grafted fab-} ric

XPS measurement was performed on a Shimadzu 3300 spectrometer employing $\operatorname{MgK} \alpha(1253.6 \mathrm{eV}) \mathrm{X}$ ray source was used. The electron take-off angle was $60^{\circ}$ with respect to the fabric surface. The pressure in the analysis chamber was maintained at $10^{-5} \mathrm{~Pa}$ during data acquisition. The $\mathrm{X}$-ray source was run at an anode voltage of $8 \mathrm{kV}$ and current of $30 \mathrm{~mA}$.

\section{4 Observation of surface morphologies}

The treated surface morphologies were observed using a scanning electron microscope (SEM)-model JEOL JSM-5200. For better electric conductivity, the sample's surface was coated with thin gold layer before the examination. The observation was performed to determine the quality of polymer depositions, and especially to check whether micropores were on the fiber surface.

\section{3 . Results and Discussion}

\section{1 Surface degradation}

The degradation of the fiber surface irradiated with He-Ar glow-discharge seems to be predominant effects of the discharge interaction on the surface polymer. This process led to a breakdown of $\mathrm{C}-\mathrm{H}$ or $\mathrm{C}-\mathrm{C}$ bonds into carbon radicals (shown in Eq. 1) on the fiber surface. Subsequently exposed to air, these radicals were reacted with oxygen in air to form peroxides and hydroperoxides (Eqs. 2, 3). ${ }^{7}$ These peroxides being initiators for the graft polymerization were formed as following reactions:

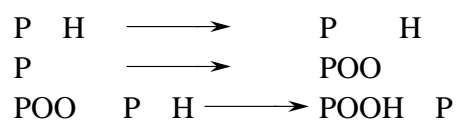

Where: $\mathrm{P}-\mathrm{H}$ is the polymer chains in the PET struc- 


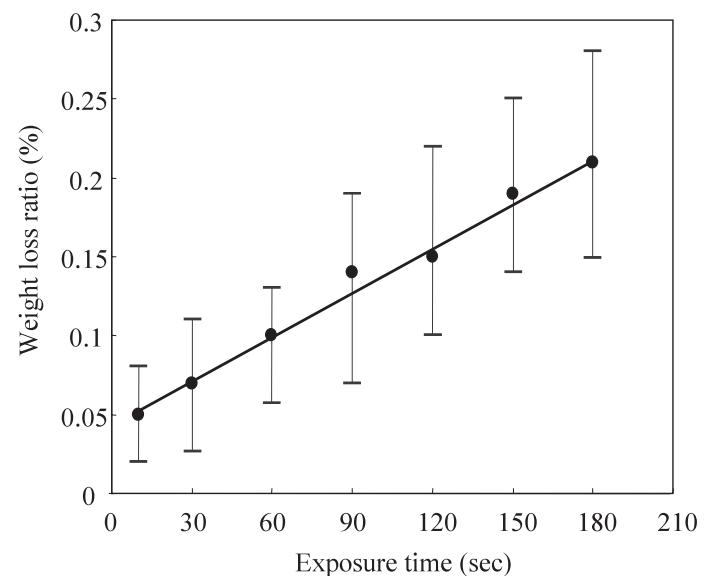

Fig. 3 Polymer degradation of the PET fiber surface treated with He-Ar plasma for different time of exposure.

ture.

The degradation of molecule chains at the irradiated surface layers versus the time of exposure is indicated in the Fig. 3. It is clearly that the weight loss ratio, indicating the level of the degradation, proportionally increased with increasing the time of exposure. The large dispersion of the weight loss may be ascribed to the effect of the density of activated species, which collided with the fiber surface and cross-linking of radicals generated on the surface during the GDP treatment. The similar results have also been found in the report of Yasuda et. al. ${ }^{4)}$ who investigated the degradation of PET film under low-pressure plasma with inert helium gas.

\section{2 Effects of the exposure time on grafting degree}

Figure 4 shows the grafting degree of the grafted fiber surface as a function of the exposure time at different grafting temperatures. The peak of the graft level was achieved at $30 \mathrm{~s}$ of the exposure time. With the further exposure, the grafting degree gradually went down then leveled off at over $90 \mathrm{~s}$. This may be ascribed to causing unfavorable etching, cross-linking and degradation of the fiber surface resulting in a no net gain of the surface-activated species for the graft polymerization that are usually accompanied with long time of exposure. When the fiber surface was heated in the presence of the monomer, the hydroperoxides decomposed to give equal number of $\mathrm{PO}^{*}$ and ${ }^{*} \mathrm{OH}$ radicals.

$$
\mathrm{POOH} \longrightarrow \mathrm{PO}^{*}+{ }^{*} \mathrm{OH}
$$

These $\mathrm{PO}^{*}$ radicals initially served as activated sites

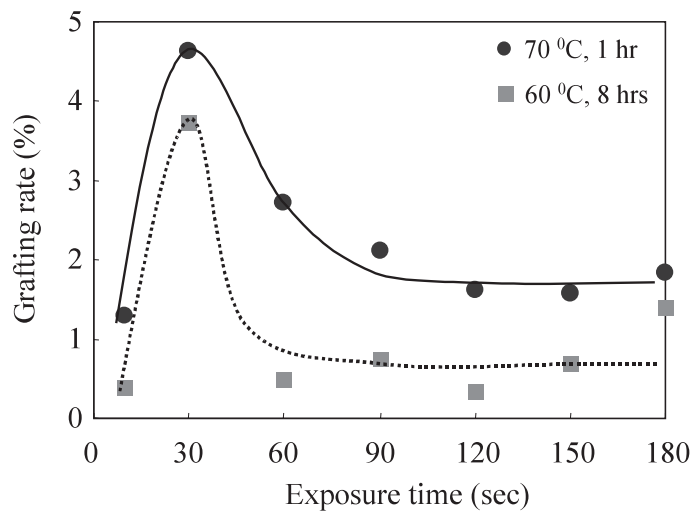

Fig. 4 Grafting degree versus the exposure time of the PET fiber fabric treated with plasma-induced graft at different temperatures.

for the grafting reaction, then reacted with AA vapor to form copolymer (Eq. 5)

$$
\begin{aligned}
& \mathrm{PO}^{*}+\mathrm{CH}_{2}=\mathrm{CH}-\mathrm{COOH} \longrightarrow \\
& \mathrm{PO}-\mathrm{CH}_{2}-\mathrm{C}^{*} \mathrm{H}-\mathrm{COOH}
\end{aligned}
$$

while ${ }^{*} \mathrm{OH}$ radicals were the direct cause of homopolymer (Eq. 6) ${ }^{16,17)}$

$$
\begin{aligned}
& { }^{*} \mathrm{OH}+\mathrm{CH}_{2}=\mathrm{CH}-\mathrm{COOH} \longrightarrow \\
& \mathrm{HO}-\mathrm{CH}_{2}-\mathrm{C}^{*} \mathrm{H}-\mathrm{COOH}
\end{aligned}
$$

Although the polymerization time decreased to $1 \mathrm{~h}$, higher grafting degree coincident with a higher amount of homopolymer was gained at grafting temperature of $70^{\circ} \mathrm{C}$ as compared to the grafting temperature of $60^{\circ} \mathrm{C}$ for $8 \mathrm{~h}$. This may be assigned to increasing in the number of free radicals generated by the thermal decomposition, resulting in more reactive sites along the polymer chains. Another effect of increasing the temperature is that it enhanced the diffusion of the monomer into the fiber. However, the higher grafting temperature than PET glass transition one led to a possibility of decreasing in the number of reactive sites on the polymer backbone of the fiber. Also at higher temperatures, AA has a higher tendency to homo-polymerize resulting in a decrease in the grafting level. ${ }^{18)}$

\section{3 Washing durability of the grafted fabric}

Figure 5 demonstrates the wicking time versus the time of exposure with the sample grafted at $70^{\circ} \mathrm{C}$ for 1 $\mathrm{h}$. The mean wicking time was taken from at least three different spots. The lowest wicking time attained around $30 \mathrm{~s}$ of the exposure time. This means the grafted fabric irradiated for $30 \mathrm{~s}$ has the highest affinity to water. More than $30 \mathrm{~s}$ as well as less than its 
time could not make the grafted fabric more hydrophilic. This result is consistent to the highest grafting degree mentioned in the previous section.

The washing durability illustrated in Fig. 5 was dependent on washing times; the wicking time increased with increasing the times of washing and leveled off when times of washing were beyond 20 times. This can be explained by decreasing amount of the copolymer on the fiber surface caused by friction between water and the fabric's surface; the reaction of the copolymer and the neutral detergent was also one of reasons to reduce the copolymer on the fiber's surface. Another reason is that hydrophilic polar groups bonded to a molecule backbone chain were reoriented themselves to surface layers resulting in the gradual deterioration of the surface hydrophilicity. ${ }^{14)}$

\section{4 XPS measurement}

The chemical compositions of the fiber surface were analyzed by XPS. Figure 6 shows wide-scan spectra

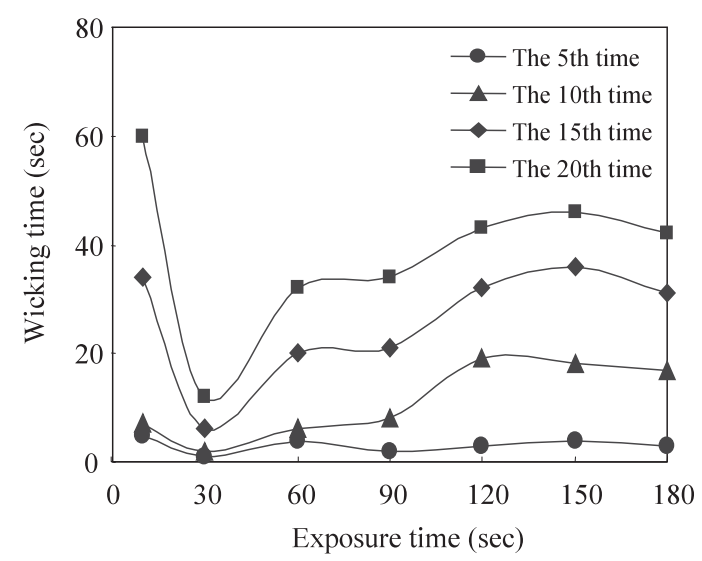

Fig. 5 Wicking time as a function of exposure time and washing times for the knit-fabric irradiated with plasma for $30 \mathrm{~s}$ and grafted at $70{ }^{\circ} \mathrm{C}$ for $1 \mathrm{~h}$.

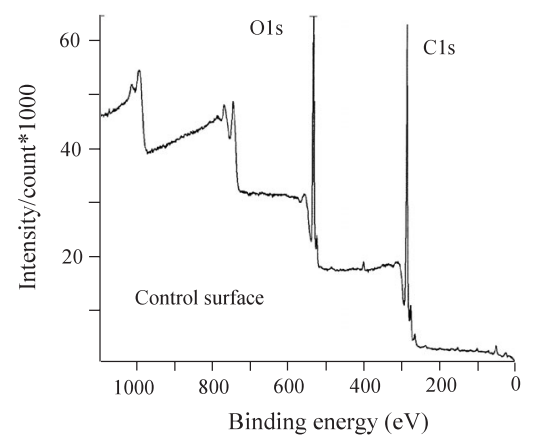

a) of a) the control and b) the surface irradiated for $30 \mathrm{~s}$ subsequently grafted at $70^{\circ} \mathrm{C}$ for $1 \mathrm{~h}$. Peaks of carbon and oxygen binding energy were at $285 \mathrm{eV}$ and 532 $\mathrm{eV}$, respectively. It is noteworthy that the relative surface oxygen and carbon atomic concentrations have been modified significantly. The $\mathrm{O}_{1 \mathrm{~s}} / \mathrm{C}_{1 \mathrm{~s}}$ ratio increased from $34.4 \%$ to $42.6 \%$ for the control and grafted surface, respectively. Clearly, the surface has been oxidized by the plasma-induced graft polymerization owing to the oxygen content enhanced from $25.6 \%$ to $29.9 \%$ correspondent to the control and grafted surface, respectively (Table 1).

Figure 7 demonstrates high-resolution scan of the $\mathrm{C}_{1 \mathrm{~s}}$ core-level spectra for a) the control surface and $\mathrm{b}$ ) the surface irradiated for $30 \mathrm{~s}$ subsequently grafted at $70^{\circ} \mathrm{C}$ for $1 \mathrm{~h}$. Lineshape analysis by break deconvolution indicates that $\mathrm{C}_{1 \mathrm{~s}}$ spectra of the control surface are composed of three distinct peaks at the binding energy (BE) of 285. 0, 286. 6 and 288. 9 eV (Fig. 7 a). These peaks can be assigned to the $\mathrm{C}^{*}-\mathrm{H}, \mathrm{C}^{*}-\mathrm{O}$ (e.g., ether, ester) and $\mathrm{O}-\mathrm{C}^{*}=\mathrm{O}$ (e.g., carboxylic acid, ester) groups, related to an aromatic ring $-\mathrm{C}_{6} \mathrm{H}_{4}-$, $\mathrm{CH}_{2}-\mathrm{CH}_{2}-\mathrm{O}$ and $\mathrm{CO}-\mathrm{O}$ groups, respectively. ${ }^{19)}$ And these assignments are also in good agreement with the structure of the PET-repeating unit described in Fig. 1 b.

$$
\left(-\mathrm{O}-\mathrm{CO}-\mathrm{C}_{6} \mathrm{H}_{4}-\mathrm{CO}-\mathrm{O}-\mathrm{CH}_{2}-\mathrm{CH}_{2}-\right)_{n}
$$

$\mathrm{C}_{1 \mathrm{~s}}$ spectra of the grafted surface consist of four peaks: one of them is a peak of carbonyl groups: $\mathrm{C}^{*}=$

Table 1 Atomic percent compositions on the surface irradiated for $30 \mathrm{~s}$ and grafted at $70^{\circ} \mathrm{C}$ for $1 \mathrm{~h}$.

\begin{tabular}{lccc}
\hline & \multicolumn{3}{c}{ Surface chemical compositions, \% } \\
\hline Treatment & $\mathrm{C}_{1 \mathrm{~s}}$ & $\mathrm{O}_{1 \mathrm{~s}}$ & $\mathrm{O}_{1 \mathrm{~s}} / \mathrm{C}_{1 \mathrm{~s}}$ \\
\hline Untreated & 74.4 & 25.6 & 34.4 \\
Grafted & 70.1 & 29.9 & 42.6 \\
\hline
\end{tabular}

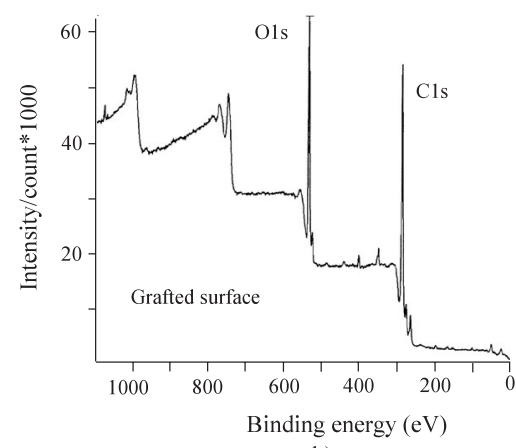

b)

Fig. 6 Wide-scan spectra of a) the control surface and b) the surface irradiated for $30 \mathrm{~s}$ and grafted at $70^{\circ} \mathrm{C}$ for $1 \mathrm{~h}$. 


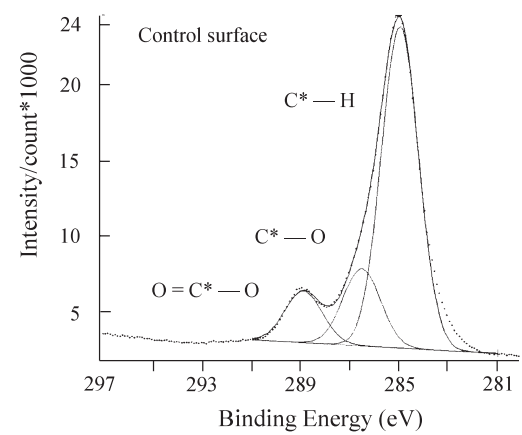

a)

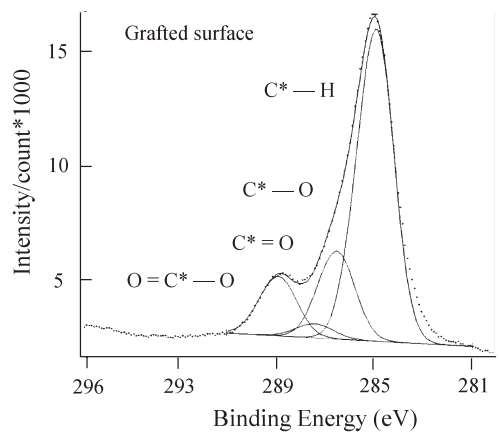

b)

Fig. 7 Line-shape analysis of the high-resolution of the $\mathrm{C}$ peak spectra for a) the control surface and b) the surface irradiated for $30 \mathrm{~s}$ and grafted at $70^{\circ} \mathrm{C}$ for $1 \mathrm{~h}$.

Table 2 Relative chemical compositions of $\mathrm{C}_{1 \mathrm{~s}}$ spectra on the surface irradiated for $30 \mathrm{~s}$ and grafted at $70^{\circ} \mathrm{C}$ for $1 \mathrm{~h}$.

\begin{tabular}{lcccc}
\hline \multicolumn{5}{c}{ Decomposition of the $\mathrm{C}_{1 \mathrm{~s}}$ peak } \\
\hline \multicolumn{5}{c}{$\mathrm{C}_{1 \mathrm{~s}}$ component, \% } \\
\hline Treatment & $\mathrm{C}^{*}-\mathrm{H}$ & $\mathrm{C}^{*}-\mathrm{O}$ & $\mathrm{O}-\mathrm{C}^{*}=\mathrm{O}$ & $\mathrm{C}^{*}=\mathrm{O}$ \\
\hline Untreated & 71.4 & 17.1 & 11.4 & \\
Grafted & 65.9 & 18.6 & 12.5 & 3.0 \\
\hline
\end{tabular}

$\mathrm{O}$ at $287.4 \mathrm{eV}$, and the rest are the same peaks on the control surface (Fig. 7 b). The relative chemical compositions of the $\mathrm{C}_{1 \mathrm{~s}}$ spectra on the PET fabric are shown in Table 2. There was a relative increase in the content of the $\mathrm{O}-\mathrm{C}^{*}=\mathrm{O}$ carboxyl group from $11.4 \%$ to $12.5 \%$, the $\mathrm{C}^{*}-\mathrm{O}$ group from $17.1 \%$ to $18.6 \%$, and also $\mathrm{C}^{*}=\mathrm{O}$ carbonyl of $3.0 \%$, the new group incorporated into the surface while the $\mathrm{C}^{*}-\mathrm{H}$ linkage of the aromatic ring decreased from $71.4 \%$ to $65.9 \%$. These data suggest that plasma-induced graft polymerization mainly involves in the modification of $-\mathrm{C}_{6} \mathrm{H}_{4}-,-\mathrm{CO}-$ and $\mathrm{O}-\mathrm{C}^{*}=\mathrm{O}$ groups while postplasma reaction in air of free radicals generated by broken chains and dehydrogenation mechanisms led to the formation of the carbonyl group, a new linkage from the $\mathrm{CO}$ group created by oxidation processes.

\section{5 Morphologies of fiber surfaces}

Figure 8 shows surface morphologies of the fiber surface non-treated and treated by plasma-induced graft polymerization with distinct magnifications. The control surface (Fig. 8 a) looks like smooth while the modified one (Fig. 8 b) seems to be rough with regular corn-structure that can be seen clearly in a SEM micrograph with higher magnification (Fig. $8 \mathrm{c}$ ). The distinction is attributed to the fragmentation of polymer chains caused by the surface etching, and to grafting the monomer onto the radicals decomposed from the hydroperoxide. It is assumed that the rough surface is one of factors that can reduce a contact angle of a droplet and therefore, decrease time for the droplet's penetration into fiber surfaces.

\section{Conclusions}

Helium-argon plasma-induced graft polymerization with acrylic acid significantly improved durable wetability of the PET fiber knit-fabric. The highest grafting degree coincident to the lowest wicking time was found when the fiber surface irradiated for $30 \mathrm{~s}$ and then grafted at $70^{\circ} \mathrm{C}$. And also, the hydrophilic durability is dependent on the times of washing: the hydrophilicity decreased with increasing the washing times, however, it leveled off beyond 20 times of washing.

The XPS characterization of the treated surface clearly demonstrates a considerable amount of the oxygen-containing functional polar groups were incorporated onto the grafted surface in the form of $\mathrm{O}-\mathrm{C}^{*}$ $=\mathrm{O}$ and $\mathrm{C}^{*}=\mathrm{O}$. It is the polar groups that improve hydrophilicity and increase surface free energy of the PET fiber surface.

The changes in morphologies of the grafted surface demonstrated copolymers like the corn-structure were incorporated on the grafted surface fiber. The grafted surface seems rougher than the control one. It is the rough surface that may reduce the wicking time of the droplet into the fiber surface.

\section{Acknowledgement}

The research was one part of the project granted by NEDO (New Energy and Industrial Technology Development Organization) from October 1998 to March 2000. The authors would like to thank professor Maekawa Zenichiro, Kyoto Institute of Technology, Graduate School of Advance Fiber Science for the useful discussion in PET fiber morphology. The 


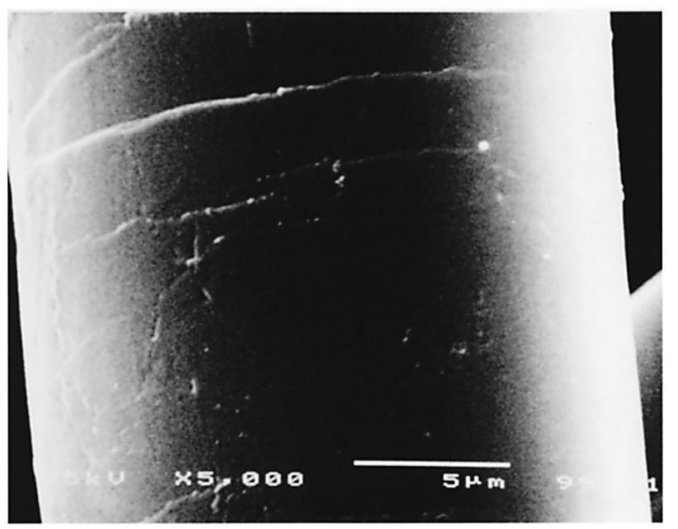

a)

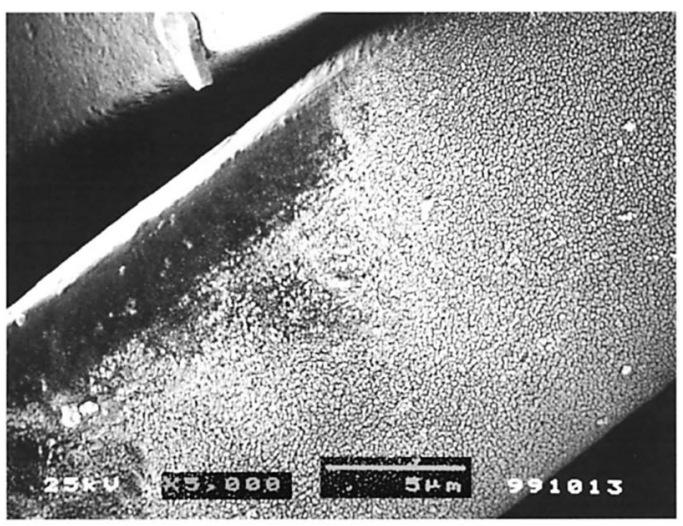

b)

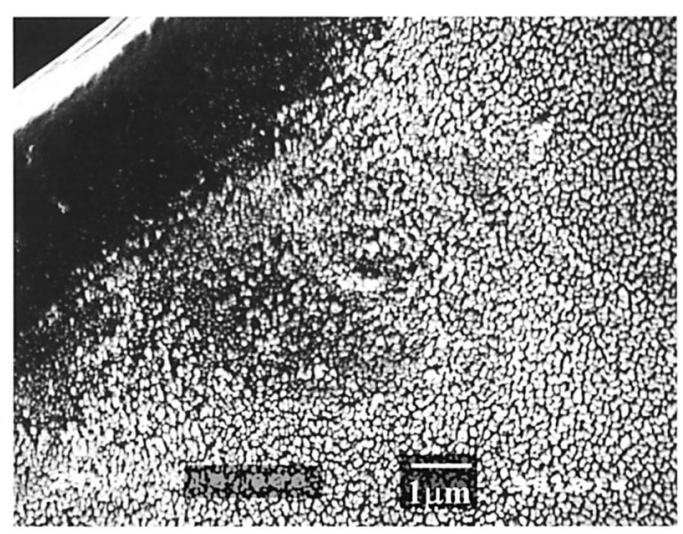

c)

Fig. 8 SEM micrographs of a) the control surface and the surface irradiated with for $30 \mathrm{~s}$ and grafted at $70^{\circ} \mathrm{C}$ for $1 \mathrm{~h}$ : b) low and c) high magnification. authors are also grateful to Dr. Mitsuru Tahara, Technology Research Institute of Osaka Prefecture, Polymer Surface Processing Division, for measurement and analysis of XPS data.

\section{References}

1) G. Gillberrg and D. Kemp: J. Polym. Sci. 26, 2023 (1981).

2) J. Buchenska: J. Polym. Sci. 65, 967 (1997).

3) H. Yasuda: J. Polym. Sci. (Macromol. Rew.) 16, 199 (1981).

4) H. Yasuda, C.E. Lamaza and K. Sakaoku: J. Polym. Sci. 17, 137 (1973).

5) J.R. Chen, X.Y. Wang and T. Wakida: J. Appl. Polym. Sci. 72, 1327 (1998).

6) S. Carlotti and A. Mas: J. Appl. Polym. Sci. 69, 2321 (1998).

7) 山上允之, 谷口節男, 林 文夫, 針谷 哲 : 染色工業 37, 613 (1990).

8) T. Goto, T. Wakida and K. Koo：繊維学会誌 47, 136 (1991).

9) A.M. Wrobel and M. Kryszewski: Polymer 19, 908 (1978).

10) N.V. Bhat and Y.N. Benjamin: Textile Res. J. 69, 38 (1999).

11) S. Kanazawa, M. Kogoma, T. Moriwaki and S. Okazaki: J. Appl. Phys. 21, 838 (1988).

12) P.P. Tsai, L.C. Wadsworth and J.R. Roth: J. Textile Res. 67, 359 (1997).

13) D.X. Pao, Y. Uyama and Y. Ikada: Kobunshi Ronbunshu 48, 529 (1997).

14) H. Yasuda and A. K. Sharma: J. Polym. Sci. Polym. Physics 19, 1285 (1981).

15) B. Gupta, J. Hilborn, C.H. Hollenstein, C. J. G. Plummer, R. Houriet and N. Xanthopoulos : J. Appl. Polym. Sci. 78, 1083 (2000).

16) T. O’Neil: J. Polym. Sci., Part A-1, 10, 569 (1972).

17) Y.C. Nho and J.H. Jin: J. Appl. Polym. Sci. 63, 1101 (1997).

18) S. Subramanian and S. Lee: J. Appl. Polym. Sci. 70, 1001 (1998).

19) D. Briggs, D.G. Rance, C.R. Kendall and A.R. Blythe: Polymer 21, 895 (1980). 